\title{
Spontaneous common bile duct perforation- a rare cause of biliary peritonitis in a patient of chronic calcific pancreatitis.
}

\section{Dr. Nandakumar B.M.}

MS Ramaiah Medical College, Bengaluru

Dr.Vivek Rajdev ( $\nabla$ vivekrajdev.43@gmail.com )

Indira Gandhi Medical College and Hospital, Shimla https://orcid.org/0000-0002-7511-8009

\section{Dr. Rakesh Gupta}

Indira Gandhi Medical College and Hospital, Shimla

Dr. Pankaj Chandel

Indira Gandhi Medical College and Hospital, Shimla

Dr. Jagdish Gupta

Indira Gandhi Medical College and Hospital, Shimla

\section{Case Report}

Keywords: chronic calcific pancreatitis, biliary peritonitis, spontaneous CBD perforation, rare cause of peritonitis, Isolated CBD perforation

Posted Date: February 7th, 2022

DOI: https://doi.org/10.21203/rs.3.rs-1330388/v1

License: (c) (1) This work is licensed under a Creative Commons Attribution 4.0 International License. Read Full License 


\section{Abstract}

Spontaneous perforation of common bile duct is a rare cause of acute generalised peritonitis. It is difficult to diagnose pre-operatively and mainly caused due to increased intra-ductal pressure of common bile duct, which can occur due to stone, stricture or malignancy.

Here, we present an interesting case report of spontaneous common bile duct perforation in a patient of chronic calcific pancreatitis leading to peritonitis, the management protocol with highlight on previous literature.

\section{Introduction}

Spontaneous perforation of common bile duct [CBD] is an infrequent cause of acute generalised peritonitis ${ }^{[1]}$. Other common causes being peptic ulcer disease complicated by duodenal or gastric perforation and unusually by gall bladder perforation. It is almost always diagnosed intraoperatively and it is a rare entity in adults. The common causes are increased intraductal pressure due to stone, tumour, stricture and erosion of a biliary diverticulum. The incidence of common bile duct obstruction among patients with chronic pancreatitis range from $3-23 \%{ }^{[2]}$. Till date only three cases of spontaneous common bile duct perforation with peritonitis as a complication in chronic pancreatitis has been reported

[3]. We report an interesting case of spontaneous common bile duct perforation in a middle-aged male with chronic calcific pancreatitis and review literature of such cases

\section{Case Report}

A 35-year-old male patient was referred from a private hospital as a non settling case of acute on chronic pancreatitis being managed conservatively for the last 4 days. Patient had complaints of generalised pain abdomen with multiple episodes of vomiting.

On examination he was sick looking and dehydrated with tachycardia, tachypnoea and was normotensive. On examination, the abdomen was distended and tender with presence of free fluid and absent bowel sounds. Initial investigations revealed haemoglobin $15.1 \mathrm{gm} / \mathrm{dL}$, white cell count 27,100 /cumm with $94 \%$ segmented neutrophils, serum bilirubin was $1.84 \mathrm{mg} / \mathrm{dL}$, transaminases and alkaline phosphatase [ALP] were normal. Serum Amylase and Lipase were $321 \mathrm{U} / \mathrm{L}$ and $393 \mathrm{U} / \mathrm{L}$ respectively. Ultrasound abdomen showed moderate ascites with multiple pancreatic calcifications. Chest X-ray was normal and abdominal X-ray showed evidence of ileus with calcification in the region of pancreas [Figure 1, yellow arrow] with no evidence of air under diaphragm. Contrast-enhanced Computed Tomography [CECT] of abdomen showed features of acute exacerbation with chronic calcific pancreatitis with multiple intraluminal calculi and normal common bile duct. Diagnostic paracentesis showed bilious fluid.

With the provisional diagnosis of biliary peritonitis, patient was taken up for explorative laboratory. Upon exploration, 1.5 litres of bilious peritoneal fluid was aspirated, omentum was studded with calcifications. 
The duodenum and stomach were normal. Gallbladder was intact and didn't contain any calculus. The common bile duct was mildly dilated $8 \mathrm{~mm}$ with a perforation of $5 \times 5 \mathrm{~mm}$ in supraduodenal part [Figure 2 , white arrow]. It didn't contain any calculus and distal patency was maintained. Cholecystectomy with primary closure of common bile duct perforation was done.

Post operative Magnetic Resonance Cholangiopancreatography [MRCP] showed smooth tapering of CBD into duodenum with acute on chronic mass forming pancreatitis with multiple calculi in pancreatic duct.

Patient had an uneventful postoperative recovery and was discharged on 6th post-operative day.

\section{Discussion}

Spontaneous extrahepatic bile duct perforation is a rare entity. Since its first description by Freeland in 1882 only 90 cases have been reported in infancy and 97 cases in adults ${ }^{[4]}$. Pathogenesis of spontaneous CBD perforation is not clearly understood. Proposed mechanisms are increased intraductal pressure due to stone, stricture \& tumour and weak CBD wall due to pancreatic juice reflux, Anomalous Pancreaticobiliary Junction [APBJ], choledochal cyst \& connective tissue disorders. Complications of chronic pancreatitis are pseudocyst [25\%], CBD obstruction [3-23\%], duodenal obstruction [0.5-13\%], pancreatic fistula and malignancy ${ }^{[2]}$. Chronic pancreatitis presenting as biliary peritonitis secondary to CBD perforation to our knowledge has only been reported three times and all three were in paediatric age group and had impacted pancreatic calculus at duodenal papilla ${ }^{[3]}$ and one patient had APBJ ${ }^{[5]}$.

Presentation is usually insidious with diffuse abdominal pain, vomiting, jaundice and patient is usually septic with raised white cell counts. Bilirubin \& transaminases are seldom deranged ${ }^{[6]}$. Absence of air under diaphragm with moderate ascites with normal gall bladder on ultrasound with a diagnostic ascitic tap showing bile should raise a suspicion of bile duct perforation. CECT abdomen is rarely informative of CBD perforation. Endoscopic Retrograde Cholangiopancreatography [ERCP] and MRCP to delineate biliary and pancreatic anatomy and Radio-nucleotide study demonstrating tracer in peritoneum is diagnostic but it is rarely done due to non availability and lack of suspicion. ERCP with stenting across perforation can be done if perforation is diagnosed preoperatively. Reports of two cases managed with

ERCP are available ${ }^{[7]}$. Spontaneous CBD perforation is almost always diagnosed intraoperatively and is usually managed with cholecystectomy with CBD exploration with primary repair or repair over T-tube ${ }^{[1]}$. In our case, primary repair of CBD was done after confirming distal patency with post operative MRCP. Biliary-enteric anastomosis is usually unwarranted in the emergency setting with grossly inflamed tissues.

\section{Conclusion}

Spontaneous bile duct perforation leading to biliary peritonitis is an uncommon diagnosis in the setting of chronic pancreatitis, but this differential should be sought when a case of suspected acute on chronic pancreatitis has diffuse peritonitis with bile in a diagnostic paracentesis. MRCP and biliary scintigraphy 
aid in preoperative diagnosis. Early diagnosis and management is must owing to its high mortality and morbidity.

\section{References}

1. Khanna R, Agarwal N, Singh AK, Khanna S, Basu SP. Spontaneous common bile duct perforation presenting as acute abdomen. Indian J Surg. 2010; 72(5): 407-408. DOI: 10.1007/s12262-010-01135

2. Vijungco J, Prinz R. Management of Biliary and Duodenal Complications of Chronic Pancreatitis. World J. Surg. 2003. 27, 1258-1270. DOI: 10.1007/s00268-003-7246-7

3. Kumar A, Kataria R, Chattopadhyay TK, Karak PK, Tandon RK. Biliary peritonitis secondary to perforation of common bile duct: an unusual presentation of chronic calcific pancreatitis. Postgrad Med J. 1992 Oct;68(804):837-9. DOI: 10.1136/pgmj.68.804.837

4. Kang Sung-Bum, Han Ho-Seong, Seog Ki Min, Kook Lee Hyeon. Nontraumatic perforation of the bile duct in adults. Arch. Surg. 2004; 10: 1083. DOI:10.1001/archsurg.139.10.1083

5. Shenoy $\mathrm{V}$, Jawale $\mathrm{S}$ et al. Anomalous pancreaticobiliary union and chronic pancreatitis: rare presentation with biliary peritonitis. Pediatr Surg Int 2001; 17: 549-551. DOI: $10.1007 / \mathrm{s} 003830000540$

6. Hamura R, Haruki K, Tsutsumi J, Takayama S, Shiba H, Yanaga K. Spontaneous biliary peritonitis with common bile duct stones: report of a case. Surg Case Rep. 2016; 2(1): 103. DOI: https://doi.org/10.1186/s40792-016-0234-6

7. Barnes Barrett H, Narkewicz Michael R, Sokol Ronald J. Spontaneous Perforation of the Bile Duct in a Toddler: The Role of Endoscopic Retrograde Cholangiopancreatography in Diagnosis and Therapy, Journal of Pediatric Gastroenterology and Nutrition. November 2006; 43(5):695-697.

DOI:10.1097/01.mpg.0000233162.43409.ec

\section{Declarations}

The patient was informed about the process of publication and the patient consented to participate in the study and publication that follows

\section{Figures}

\section{Figure 1}

Abdominal X-ray showing calcification in the region of pancreas (yellow arrow) 
Figure 2

A perforation of $5 \times 5 \mathrm{~mm}$ in supraduodenal part of CBD (white arrow) 